\title{
'Use your words': Vocalization and moral order in an oral preschool classroom for deaf or hard-of-hearing children
}

\author{
K R I S T E L L A M O N T E G E L \\ University of California, Los Angeles, USA
}

\section{A B S T R A C T}

This ethnographic study examines deaf or hard-of-hearing children's socialization in an oral classroom, a setting designed to promote spoken language as the primary mode of communication. Drawing from nine months of observations, I describe how the meanings assigned to children's vocalizations create a system of values and judgements that organizes and regulates classroom behavior. Specifically, vocalization itself is oriented to as a moral practice that is necessary for the mutual understanding and accomplishment of classroom activities. Informed by ethnomethodological and language-socialization perspectives, I illustrate how participants co-construct a local moral order wherein students are held accountable for 'using their words' to perform social actions. Analyses discuss three interactional contexts where moral issues are routinely constructed as contingent on and resolvable through vocalization - children's help-seeking, children's disputes, and negotiations of classroom participation - thereby shaping children's understanding of language use and reflecting broader institutional expectations and ideology regarding oral communication. (Moral order, preschool children, socialization)*

\section{N T R O D U C T I O N}

\begin{abstract}
The class is gathered on the floor for Morning Meeting. Ivan is fixated on his shoes and fidgets with untied shoelaces. He juts out one leg towards Ms. Brooke and gazes up at her. "What?" she asks, shrugging her shoulders. He glances down at his shoe. "Do you need help?" she prods. Ivan nods. Ms. Brooke continues, "You need to tell me. Say, 'I need help. Can you tie my shoe please?"' Ivan repeats back, softly. Ms. Brooke smiles. "Good job," she says, as she ties his shoe. "We need to use our voices, okay?"
\end{abstract}

This excerpt illustrates a common occurrence in the distinct cultural setting of a US-based oral preschool classroom for children who are deaf or hard-of-hearing (D/HH). ${ }^{1}$ When recruited to tie a student's shoe, Ms. Brooke, a teaching aide, plainly understands what she is being asked to do, but postpones her assistance in favor of eliciting spoken language from the student, Ivan. Only after Ivan vocalizes what he needs does Ms. Brooke grant his request and provide the help that was sought. Thus, in this seemingly casual and cursory exchange occurring outside of 
the primary class activity, the teaching aide provides a brief, impromptu lesson on the value of vocalization, ${ }^{2}$ situated in the context of help-seeking as a social activity important for learning. By making the student's speech —or, rather, LACK of speech - an object of concern, Ms. Brooke reveals the morality of spoken language as a constitutive feature in the everyday lived experiences of the classroom.

This article builds from research on children's active participation in their social worlds (Mayall 2002; Corsaro 2017), with a particular ethnographic focus on how the mechanisms of moral meaning-making and understanding in interaction (Garfinkel 1967; Tappan 2006; Turowetz \& Maynard 2010) socializes D/HH children to the goals of their oral classroom, as well as on the broader ideological beliefs of oral-language use. In this way, I contribute to research that views morality as occurring IN and THROUGH interaction and situated activity (Rawls 2010, 2012; Maynard $\&$ Turowetz 2013). However, while scholars have investigated the construction of moral meanings through WHAT and HOw things are said in children's interactions with others (that is, through meaning constructed through grammar, syntax, indexicality; Wainryb \& Recchia 2014; Niemi 2016; Kyratzis \& Köymen 2020), not as much scholarship has focused on how the act of speaking, apart from its content/the action it performs, can be a moral one in itself. This is especially visible with young D/HH children for whom 'using your words' is not as easy (relative to hearing children), and whose sign or spoken-language education are inherently moral decisions. This article investigates how vocalization in a $\mathrm{D} / \mathrm{HH}$ oral classroom constitutes a set of mundane 'rules' at both a locally organized and institutional level; that is, vocalization is presented as obligatory for producing social actions and maintaining intelligible interaction, which simultaneously reinforces the educational program's beliefs regarding oral communication. To my knowledge, this study is the first to examine the moral socialization of $\mathrm{D} / \mathrm{HH}$ children in an oral preschool classroom.

\section{RESEARCH C O T EX T B A C K G R O U D}

In the American education system, preschool refers to non-compulsory, schoolbased early childhood education for children ages three to five. Under the US Individuals with Disabilities Education Act (IDEA), if a child is identified as deaf or hearing impaired they may become eligible for a range of resources including free special education services and supports in public schools, starting in the preschool years. ${ }^{3}$ Students who receive special education must also have an Individualized Education Program (IEP), a document mapping out the child's learning goals, support services, and appropriate placement throughout their schooling. Placement options for $\mathrm{D} / \mathrm{HH}$ children can include, but are not limited to, mainstream classrooms with $\mathrm{D} / \mathrm{HH}$ support services, state residential programs, or oral, sign language, or total communication programs.

Placement is largely influenced by whether the child communicates through sign or spoken language (or both), a decision that underlies two competing ideologies, 
the cultural versus pathological view of $\mathrm{D} /$ deafness, with the former embracing deafness and sign language as features of a unique cultural and linguistic group, while the latter regards hearing loss as a disability to be 'fixed' toward developing language convergent with hearing peers (Pray \& Jordan 2010). ${ }^{4}$ However, educational options are not necessarily equally available to any given family. The IDEA refers to $\mathrm{D} / \mathrm{HH}$ students as a low incidence population but requiring highly specialized services. Because of this, schools often face difficulties providing adequate instruction, especially in rural areas where resources and qualified personnel are scarce (Bowen \& Ferrell 2003). Thus, D/HH children are not always placed in an educational 'option' by virtue of parents' affirmative or proactive choice. Instead, placement is often based on what is available within a reasonable distance from the child's home, and families may find themselves operating inside an ideology that they did not actually choose.

An oral program under a broader auditory-oral/verbal approach for $\mathrm{D} / \mathrm{HH}$ children is one option for families who decide to pursue listening and spoken-language instruction. ${ }^{5}$ Historically, oral programs in the US do not teach sign language and instead promote spoken language as the dominant mode of communication, based on the notion that $\mathrm{D} / \mathrm{HH}$ children can develop their residual hearing and gain speech skills through appropriate auditory technology and abundant language-rich activities. These programs are generally designed to prepare children for transitioning into mainstream educational settings. In essence, the philosophy behind oral classrooms, situated within the larger sociopolitical context of sign or spoken-language education in the US, represents a form of language ideology, or the 'beliefs or feelings about languages as used in their social worlds' (Kroskrity 2004:498), and one based on communication modality, rather than on linguistic variation (Riley 2011). While the primary pedagogical objective of oral education for $\mathrm{D} / \mathrm{HH}$ children is clear, what remains less clear is How students come to accept and adopt the values, beliefs, and expectations of their oral-educational environment. This article investigates these processes using the theoretical frameworks of moral order and language socialization.

\section{MORALITY AND MORAL ORDER}

While the definition of morality remains fractured across the social sciences, it generally refers to ideas of what is right, good, and fair (Hitlin \& Vaisey 2010). For sociocultural perspectives, a key feature of morality is that it is inextricably tied to language; thus, children's moral development is an inherently relational process, one mediated through discursive practices and shaped by the cultural context in which it occurs (Tappan 2006). This study takes an ethnomethodological approach to morality, wherein moral reasoning is treated 'as a property of the embodied interactional practices by which members of society engage' (Turowetz \& Maynard 2010:503). Ethnomethodology is the empirical study of members' taken-forgranted methods for common-sense knowledge and understanding (Garfinkel 
1967), and how, through their social actions, they create and maintain the recognizably orderly properties of their social setting (Heritage 1984). Important for this approach to morality is Goffman's (1983) notion of the 'interaction order', or the ways in which people are committed to concerted, meaningful action in order to fulfill the needs of their social selves. Goffman argued that face-to-face interaction is organized around 'ground rules' that protect and maintain the presentation of self in situations of co-bodily presence, which, in turn, places internal constraints on the interaction order that motivates individual compliance (Rawls 1987). This notion has largely influenced ethnomethodology's conception of social and moral order (Heritage 1984, 2001), but rather than based on social-self requirements, order is based on mutual trust in others to comply with and cooperatively preserve the 'background expectancies' about interaction that allow us to effectively communicate in society (Garfinkel 1967; Watson 2009; Rawls 2010).

Institutions such as schools do not order action but instead are constituted by and accomplished through the shared understandings and situated practices specific to that social situation. Moral meanings, then, are embedded in these constitutive practices (Watson 2009; Rawls 2010). Specifically, constitutive practices create an order that underpins moral action and behavior and entails participants' commitment to 'the mutual attention and egalitarian reciprocity that it requires' (Rawls 2012:503). As such, violations of these practices alter common-sense reasoning, create confusion, disrupt the orderliness of activities, and, consequently, are socially accountable (Garfinkel 1967; Jayyusi 1991; Samra-Fredericks 2010). In brief, I conceptualize moral order according to Garfinkel's assumption that social order is intertwined with moral order in that the production, organization, and the intelligibility of interaction is itself morally ordered; therefore, moral order is emergent and co-constructed in the course of discursive or embodied activities (Heritage 1984; Turowetz \& Maynard 2010).

\section{A N G U A GE, S O C I A L I Z A T I O N, A N D I D E O L O G Y}

Where Garfinkel only partly scrutinized the interconnection between members' linguistic competences and social orderliness (Garfinkel \& Sacks 1970), this link is emphasized in other fields and analytical frameworks, including the linguistic anthropological paradigm of language socialization (Schieffelin \& Ochs 1986). For the present study, the link between moral perspectives and children's (and teachers') methods for understanding seems an indispensable part of investigating how $\mathrm{D} / \mathrm{HH}$ children learn to become competent oral communicators; thus, a language socialization approach is optimal for exploring not only how children come to understand certain moral values, but also how these values matter for the organization of interaction. Language socialization concerns 'socialization through the use of language and socialization to use language' (Schieffelin \& Ochs 1986:163). As children interact with adults and with each other, they are socialized to both the discourse practices of their speech communities, as well as the 
community's broader values, identities, and notions of power and knowledge through those exchanges (1986). In other words, children's understandings of moral meanings are socioculturally constructed through the language routines in which they participate, routines which are themselves shaped by various sociopolitical and economic influences (Kulick \& Schieffelin 2004). Languagesocialization researchers apply this concern to establish micro-macro links between how local, interactional practices reinforce larger-scale social structures and systems, such as morality and power relations.

Importantly, language socialization can shape language ideologies, where certain beliefs and feelings are held about the language itself, its speakers, and its use (Schieffelin, Woolard, \& Kroskrity 1998). Language ideologies, 'whether explicitly articulated or embodied in communicative practice' (Kroskrity 2004:496), are imbued with moral issues that spread across given communities and are subject to the social positioning of its members. Much of this research has examined multilingual communities, analyzing issues such as children's exposure to certain language practices used by adults, as well as which language practices are given restrictions or higher status and prestige (Howard 2017). Most notably, Riley (2011) discussed how values can be assigned to communication modalities themselves, thereby revealing the implicit rationalizations of superiority in some language forms over others-for example, oralism over manualism. This, Riley described, gives rise to moral ideologies, which can 'influence social structures and practices in ways that obstruct or facilitate socialization' (2011:499). In the $\mathrm{D} / \mathrm{HH}$ oral preschool classroom, in particular, as children acquire spoken language, they are simultaneously being socialized by teachers to certain ideological and cultural messages of oral communication itself.

\section{CHILDREN'S INTERACTIONS AND CLASSROOM MOR A L ORDER}

A language socialization approach to morality in the $\mathrm{D} / \mathrm{HH}$ oral classroom explores how everyday communicative routines provide a vehicle for the teachers and students to construct and understand the meanings of the larger moral order of their social environment. Exploring the link between children's language and moral order has been studied across a range of preschool contexts (cf. Goodwin \& Kyratzis 2007), such as during children's arguments (Björk-Willén 2018; Moore \& Burdelski 2019) and in their play activities (Danby \& Baker 1998; Kemp \& Kyratzis 2018). This literature highlights how moral meanings are socialized into children through their attachment to particular interactional practices that adults respond to in various ways.

Most pertinent to this study is the extant literature on the communicative practices that adults use in getting children to use their words to express themselves (Kyratzis \& Köymen 2020), which is demonstrated in various contexts, such as when socializing children into morality and affect through 'emotion talk' (Cekaite 
2013; Cekaite \& Evaldsson 2020), where adults can engage children in talk about feelings and the management of social relations. These socialization processes frequently occur during children's peer conflicts. For example, Kyratzis \& Köymen (2020) described how adults can intervene in conflict by encouraging children to verbalize their affective stances in order to highlight a peer's actions as transgressive and in need of remedy, thus sensitizing children to other's feelings. The authors revealed how affective discourse can be shaped and recycled by both adults and children in the unfolding interaction, which creates opportunities for moral meaning-making and negotiation towards resolving the conflict and restoring social order.

Similarly, in his work with Japanese children, Burdelski (2010) illustrated how teachers encourage children to be other-oriented — which reflects the larger institutional goals of developing children's kindness and empathy - through two main discursive strategies: (i) prompting children on what to say in their peer interactions (e.g. Say thank you), and (ii) reporting the speech of one child's prior expression in an effort to encourage another child's response (e.g. She said thank you). Not only do these strategies socialize children into politeness, but teachers can use them to mediate children's peer conflicts and encourage them to resolve problems on their own (Burdelski 2020), thereby guiding children to use language to respond in appropriate, empathic ways (Burdelski 2015).

Examining children's conflicts can reveal how moral accountability for antisocial or inappropriate behavior is locally accomplished in situ (cf. Moore \& Burdelski 2019; Cekaite \& Evaldsson 2020), as well as how children's use of spoken language is treated as necessary for correcting such behaviors (Kyratzis \& Köymen 2020). For example, Tobin, Wu, \& Davidson (1989:167) argued that a key lesson taught in American preschools is that 'words and reason are preferable to fists in conflict resolution', demonstrated through teachers' sanctioning of children's fighting in favor of their verbal articulations. Similarly, while children may use crying as a resource in attracting a teacher's attention towards resolving transgressions committed against them (Holm Kvist 2018), teachers may treat crying as inappropriate or 'babyish' and instead encourage children to express their feelings with words (Ahn 2016).

In a Swedish context, Cekaite (2012) explained how children's tattling not only reveals their understandings of blame attribution, but how teachers can intervene by employing various questioning practices to solicit children's tellings and accounts of how and why the conflict took place. Furthermore, teachers can socialize children into perspective-taking by soliciting multiple tellings and having the children listen to each other's version of the problematic event, in what Cekaite (2020:3) referred to as 'the triadic/multiparty participation framework of moral accountability'. Of course, teachers can also intervene by socializing children to apologies, which may involve teaching children the 'right' and 'wrong' ways of apologizing and the discursive practices that each entail (Björk-Willén 2018).

The abovementioned body of literature is especially remarkable in its explications of how even preschool-age children are adept in developing and 
understanding social organization through language. Taken together, these works illustrate how children's moral socialization does not only occur through exposure to the knowledge and language practices of their community, but also through their active participation in - and reproduction of - them.

\section{THE PRESENT ST U DY}

Given that spoken language is prioritized in the oral classroom, this study explores how children and teachers establish the act of vocalization as valued, regulatory, and constitutive of a moral order that shapes classroom interaction in an orderly way. In the oral classroom, not only activities and lessons, but also the general progression of the day is virtually entirely organized to promote oral communication. The children do not necessarily have access to this bigger picture; instead, they are socialized to this through the meanings that are assigned to vocalization, which are revealed instance-by-instance through participation in everyday interactions with both teachers and peers.

While the moral significance of speaking may be implied in much interactional research, the main theoretical contribution of this study is that it makes explicit vocalization as a constitutive practice (Watson 2009; Rawls 2010), used towards shared reasoning and social action necessary for classroom activities. My analysis shows how the routine prompting of children's vocalization is both facilitated byand is reinforcing of - the institutional expectations of formal oral-educational programs, as well as a broader oral-language ideology.

\section{E T H O D O L O G Y}

I use ethnography to investigate how moral order emerges in the participation structures of a D/HH oral preschool classroom. In November 2017, I became a volunteer in one oral classroom and subsequently visited the class once a week for nine consecutive months, taking field notes while I assisted in the daily activities. The oral classroom is specifically for $\mathrm{D} / \mathrm{HH}$ children, though it is part of a larger specialeducation preschool located in Southern California. The preschool serves children ages three to five with special needs including cognitive, language, physical or motor, and social-emotional diagnoses and eligibilities. The oral classroom is equipped with a wireless pendant microphone for the teacher and speaker system to amplify sound. The class lasts from 8:00AM to 1:00PM each weekday, and the daily schedule, posted on the classroom front door, lists the following activities: Math and Play, Morning Meeting, Breakfast, Circle Time, Literacy Centers, Recess, Library, Lunch, Dramatic Play, Music, and Time to go Home. This study was approved by a Research Ethics Review Board, as well as the board of the school district. Ethnographic observation was the methodology agreed upon by the school; however, I was given permission to conduct audio-visual recordings during my second year of volunteering (in 2018-2019; see Montiegel 2021). 
Thus, this study stems from my initial year in the classroom, though it is part of a larger research project.

\section{P A R T I C I P A N T S}

All participants' names in this project have been replaced with pseudonyms. The class has one main instructor, Ms. Kate, who is herself deaf and oral and has a cochlear implant. There are two teaching aides, Brooke and Yolanda, both of whom are hearing. Six preschoolers were enrolled in the class at the time of my first visit; however, since children may be placed in or out of the class at any point during the school year per their IEP evaluations, the total number of students in the class during the observation period varied between five to eight. Jesse and Irena (age five) are in their last year of the program and will subsequently transition into kindergarten. Brian, Aaron, and Ivan (age four) are in their second year of the program. Beaux (age three) is in his first year of the program. Evie and Johnnie (ages three and five, respectively) are the newest students and were brought in during the spring. All students have hearing loss but to varying levels and configurations, and most students wear some form of a hearing assistance device. Some students in this study have hearing loss alongside other conditions such as speech and language, learning, or behavioral disorders. All students in this study are children of hearing parents, as are the majority of D/HH children in the US (Mitchell \& Karchmer 2004). The students come from Hispanic, Asian, and Caucasian ethnic backgrounds. Spoken language is the primary mode of communication in students' homes, with English as the native language, except for Aaron and Beaux, who live in Spanish-speaking households.

\section{A T A C O L LE C T I O N}

Data consist of extensive field notes taken during my volunteering. The center was chosen based on a personal connection I had with the instructor of the oral classroom, which facilitated access to the research site and allowed me to more swiftly develop relationships with the students and teaching aides. In this classroom, it was not uncommon for outside adults (e.g. speech pathologists or administrators) to visit the class and record their written observations or assessments of student progress, which allowed me to conduct my own ethnographic notetaking of events in real-time (or immediately after they occurred) and also enhanced the accuracy of the data, especially in documenting participants' quotations. During the initial month of visitations, I assumed the role of student observer and sat to the side of most activities, taking notes on the general design and routines of the classroom. By the second month, the instructor had immersed me in the activities of the daily schedule, elevating my role in the class from an observer to an engaged participant of the setting. I assisted the instructor and teaching aides with different tasks including reading stories, supervising playtimes, joining mealtimes, and 
practicing literacy and counting. Throughout data collection, upon returning home from the classroom, I revisited my notes and added as much description of my observations as I could remember.

The initial, broad aim of this study was to examine how members of a D/HH oral preschool classroom actually put an oral-educational approach into practice. I inductively analyzed the field-note data through an iterative process of open coding and memos in order to identify patterns and develop analytic categories as they emerged. The theme of vocalization manifested as a distinct type of social phenomenon in the setting, and through theoretical sampling of the data excerpts (Charmaz 2006), I was eventually able to interpret vocalization as part of a larger concept of moral order.

\section{A N A L Y S I S}

I make several claims concerning vocalization in the oral classroom. First, vocalization is highly valued, such that students are held morally accountable for using spoken language to perform social actions. Second, facilitating learning and building children's dispositions to use their voice are achieved not just through formal institutional structures (e.g. IEP goals, curricular activities), but through the implicit messages that children are socialized to in their daily interactions during various classroom activities. Third, it is through the meanings given to vocalization that the teachers and students actively co-construct a moral order that prescribes and proscribes behavior in the oral classroom. This moral order supersedes all other moral conduct (e.g. using manners) or local orders (e.g. classroom management); that is, the presence/absence of students' vocalization is more strongly oriented to by participants as the object of moral concern.

Evidence for my claims is described through three main interactional activities in which participant orientations to a local, moral order were recurrently made visible: (i) When children seek help, (ii) during children's disputes, and (iii) when negotiating class participation. These contexts themselves frequently entail moral issues due to the nature of the exchange; however, analyses show how students' vocalizations were routinely oriented to as holding stronger moral implications than other issues present. The subsequent section discusses how the moral imperative of vocalization (specifically, sTUDENTS' vocalized efforts) is revealed in each of these situated activities.

\section{Children's vocalization when seeking help}

The moral order in the classroom is perhaps most frequently illustrated in exchanges where a student wants or needs something and solicits a teacher's assistance or provision of whatever is sought, as in the case with Ivan and his shoes at the beginning of this article. In another exchange with Ivan, described below, the class is gathered at the table for breakfast. The table is shaped like a semi-circle, and Ms. Kate sits on one side facing the students. Yolanda brings out a tray of breakfast items and places it on the table. 
Ivan sprawls across the table and reaches for a donut. Though the tray is out of reach, it is clear he desires one, but Ms. Kate doesn't give one to him and instead asks what he wants. "Donut," Ivan replies. "Donut what?" she asks again. Ivan hesitates and slinks back into his chair. "Can you say it nicely?" Ms. Kate requests. "I want a donut," Ivan says tenderly. "Okay. You want a donut. Here you go!" approved Ms. Kate, as she places one onto Ivan's tray.

At a first glance of this exchange, the moral dimension might seem inseparable from politeness and, thus, no different than what we can expect in any preschool. That is, it is generally understood that children are socialized by adults to follow conventional rules of politeness, which includes polite language (Burdelski 2010). In declining to give Ivan a donut, Ms. Kate takes a moral stance on a more virtuous way to 'get what you want'. Namely, 'saying it nicely' entails respect or kindness, and since Ivan was asked to provide such an expression, his actions prior to the instructor's request are retrospectively evaluated as discourteous. Closer inspection, however, reveals an underlying moral element centered on developing students' habits of using their voice - on getting students to use speech as much as possible - rather than primarily on politeness. Ms. Kate repeats, and thus highlights, what Ivan wants and continues to pursue his verbal request even after he withdraws, revealing that her agenda is not on giving him the donut, it is on prompting him to articulate his desires. Note that what Ivan responds with is DEVOID of any typical markers of politeness, as "I want a donut" is not traditionally interpreted as well-mannered; it lacks the magic word 'please' and uses 'want' rather than the politer 'would like' or 'May I have'. Yet, Ms. Kate accepts his reformulation and gives him his treat. In short, Ivan's request does not meet conventional standards of politeness, though it does meet a different moral standard of vocalization. The instructor engages in a moral lesson of sorts, orienting to not the obligation of polite language, but rather, to the obligation of maximized vocal communication, socializing Ivan to this standard by manipulating his want into a reward in exchange for his compliance (Devries \& Zan 1994). In the oral classroom, socializing children into saying something 'nicely' appears to transcend kindness or courtesy to include communicating vocally and, thus, 'properly'.

From this case alone, there are traces of evidence that reveal how students' vocalizations are prioritized over other moral matters such as basic politeness in the oral classroom. We can begin to uncover this with supplemental cases absent of any particular preferences held by the teachers, illustrated in the next excerpt.

The class gathers at the table for an applesauce-making activity. Apple slices are placed on a paper towel in front of each student. They're instructed to cut the apples into small pieces with a plastic knife. The pieces will be smashed in one large bowl. The students are absorbed with the activity, and the adults keep a watchful eye to ensure that the students avoid cutting their fingers. After several minutes, Brian exclaims, "Kate! I need the bowl, Kate!" Ms. Kate slides the bowl toward Brian and says, "Oh, I like how you used your voice, Brian. Good job."

Unlike the previous examples, in this exchange, Brian's first attempt at requesting his need is vocalized ("Kate! I need the bowl, Kate!"). This request, urgent and entitled, is difficult to characterize as polite. Yet, Ms. Kate not only immediately 
grants the request, but she also praises Brian for using his voice, even personalizing her praise by characterizing vocalization as something she herself admires. In this way, the instructor's remark conveys her own positive attitudes towards spoken language. It also attributes agency to Brian through his voluntary use of speech and exemplifies his actions as a model of good behavior. Her communicative practices in response to Brian's unsolicited use of speech demonstrate ways in which naturally occurring interaction functions as a mechanism in the co-construction of moral meanings and a larger classroom order.

Aside from teachers' moral evaluations of the children's 'nice talk', the children THEMSELVES display their understandings of the normativity of vocalizing needs/wants, thus constructing and reconfirming vocalization as a moral practice in their classroom interactions. In the next example, the class is gathered at the table for breakfast. Cinnamon rolls have been distributed to the students.

\footnotetext{
Johnnie hastily finishes his cinnamon roll, then points to the remaining rolls on the table and blurts, "Cinnamon roll!" Ms. Kate is facing away from Johnnie and does not hear him. "Cinnamon roll," he says and points again. Ivan, who has been watching Johnnie from across the table, says to him, "I want more cinnamon roll." Ms. Kate does hear this, but she mistakenly asks Ivan if he would like another. Ivan shakes his head, "No, Johnnie has to say it." He then looks at Johnnie and remarks, "Say 'I want more cinnamon roll,", to which Johnnie complies. Ms. Kate transfers another roll to Johnnie's tray and says, "Oh, Johnnie, YOU would like more cinnamon roll. Thank you, Ivan, for showing him how to ask nicely."
}

At this point in the analysis, we have seen how extended forms of vocalization constitute the idealized format of communication when students produce requests. In this excerpt, Johnnie's indirect request for a cinnamon roll is oriented to as a communicative breach NOT by a teacher, but rather, by one of his peers. Ivan has been monitoring Johnnie's unsuccessful attempts and treats his initial utterance as insufficient by offering a solution with the extended reformulation, "I want more cinnamon roll", asserting to the instructor that the expression is one in which Johnnie is obliged to speak ("No, Johnnie has to say it."). Additionally, Ivan explicitly instructs his peer on the appropriate way to communicate what he wants ("Say 'I want more cinnamon roll'"). When Johnnie indeed repeats this statement, he both accepts and follows the help given by his peer and ultimately receives the dessert he desired. Thus, in this exchange, we see how children themselves can uphold the classroom's social-moral order through the practices of peer monitoring and prompting. In line with previous research on prompting as a languagesocialization practice (Burdelski 2010, 2015), in this example, a child prompts his peer on what to say back to the adult; that is, Ivan holds Johnnie accountable for what he knows (or ought to know) about the classroom norms regarding vocalization when asking for something, thereby reinforcing it as a moral 'rule'.

To summarize, being vocal is assigned moral value by participants and is socialized as a normative part of the classroom culture through the interactional routines that take place. Although moral perspectives are instilled in children through their learning of behavioral codes such as manners and politeness, in the oral classroom, 
what pervades these codes is a stronger orientation to vocalization, such that building children's habits of using speech is imbued in every aspect of the classroom's daily life. The examples so far have also shown that, when students make requests to teachers, the teachers can work to control the definition of the situation by delaying or even denying granting the request, to the extent that it is no longer about providing students with what they wanted or needed, but rather, it is about rewarding them for what they have earned through their vocalized efforts. Thus teachers transform even mundane moments (e.g. students' requests) into instructional exercises on spoken-language use.

\section{Children's vocalizations in peer disputes}

Like positive evaluations or rewards, sanctions and punishments can also reveal classroom moral values, which frequently occur in instances of classroom trouble. Teacher mediation of children's disputes frequently involves practices for soliciting children's speech towards conflict resolution (Moore \& Burdelski 2019). For example, conflict mediation can involve a moral dialogue with the offending students, where the teacher asks questions to both reconstruct the dispute and solicit accounts for its occasion (Danby \& Baker 1998; Cekaite 2012). These events may revolve around some severe transgression in the classroom's social-moral order, such as physical acts of force or aggression (Tobin et al. 1989); however, in the oral classroom, the morality of vocalization recurrently transcends whatever the nature of the trouble, surfacing precisely because participants orient to the absence of vocalization on occasions where it is normally expected. Consider the following episode, wherein Ms. Kate catches Brian and Jesse in the middle of a physical altercation that is centered on the rights to a toy truck.

\footnotetext{
"WHOA!" cries Ms. Kate, as she intervenes and takes hold of the toy. She crouches down to the boys' eye-level and holds their hands. Her voice is calm but firm. "We don't hit. Okay? That's not nice. We talk out what happened." She looks at Jesse and says, "Brian was playing with the truck first." Jesse complains that he wants to play with the truck too. Ms. Kate urges, "But you have to ask if you want to play too. You both have to share, you don't just grab things when someone is playing with them." The boys stand silently. She then looks at Brian. "If you're not done playing then what are you supposed to say? You need to use your words." Brian stays quiet. She continues, "You say, 'I'm using this truck first. You can use it when I'm done'." Brian mumbles her exact words. "Good," affirms Ms. Kate. "So, what do we say?" The boys exchange "sorrys" and Ms. Kate excuses them back to play-time.
}

Here, Ms. Kate witnesses the transgression but forgoes a solicitation of accounts from the boys and directly invokes the basic moral principle of 'no hitting', a principle found in virtually any preschool setting. However, although this prohibition characterizes hitting as a recognizable act that is morally offensive ("That's not nice"), an explanation for the violation is not sought from either of the boys. Instead, Ms. Kate immediately appeals to the moral alternative to hitting - the interactional practice of 'talking it out' — and treats it as a known-in-common practice for managing classroom conflict that should be adhered to by all members. She holds both boys accountable for neglecting to vocalize their intentions with the 
truck, with Jesse having failed to ask to play with the truck, and Brian having failed to acknowledge Jesse's request. Furthermore, Ms. Kate associates the speech act of asking with the prosocial behavior of sharing, casting Jesse's act of grabbing as a social infringement. Of special note, however, is her orientation to Brian's role in the dispute. Her question, "what are you supposed to say?" presumes Brian as already knowledgeable of the appropriate conduct expected in these kinds of situations. Consequently, his initial noncompliance with the normative culture is framed as a breach in the order of the classroom, and it is from this breach that the moral order is more clearly displayed, as it demonstrates participants' awareness of its existence (Garfinkel 1967; Jayyusi 1991; Samra-Fredericks 2010). Ms. Kate then prompts Brian to articulate his preferences as a proposed solution for the dispute, "I'm using this truck first. You can use it when I'm done" (cf. Burdelski 2010, 2020; Cekaite 2020). Only when Brian recites the solution, and after the boys exchange verbal apologies, does Ms. Kate treat the dispute as settled.

The boys' dispute illustrates the careful moral work that the instructor employs to both regulate children's behaviors and simultaneously encourage their selfregulation by inculcating the importance and practicality of spoken language. This parallels similar studies that have examined how teachers pursue children's speech when guiding them on how to interpret and respond to another's actions (Burdelski 2015; Kyratzis \& Köymen 2020) or when socializing them into perspective-taking (Cekaite 2020). However, Ms. Kate reframes the boys' problem as one that is principally centered on (their omission of) speech, thereby necessitating a solution as one that can ONLY be accomplished vocally. Vocalization in this example involves not only teaching the boys what to say to navigate such interpersonal conflicts, but also engaging them in a verbal exercise on conflict management. In this way, the teacher ritualizes the event by organizing the dispute as a particular type of social encounter with customary vocal practices and strategic moves that are performed to manage perceptions and maintain the larger social order (Goffman 1981). This socializes the boys to the belief that vocal behavior is the standard behavior in these exchanges.

Pushing is another antisocial behavior and moral transgression that frequently occurs in students' conflicts. In the next excerpt, the students are playing with toy trains on the floor. Aaron's leg is blocking one area of the train tracks. His back is turned to Brian, who is trying to get his train to pass.

Brian pushes Aaron's back and shrieks, "Move!” Ms. Kate promptly exclaims, "Uh-uh! No hands! What do you say?" Brian looks stunned and answers, "I want him to move." Ms. Kate replies, "Okay, then can you ask him nicely instead of pushing him? We don't push. Tell Aaron what you'd like him to do." Brian does as he's told. Aaron scoots over to the side so that he's no longer blocking the tracks. Ms. Kate nods and allows them to continue playing.

Ms. Kate initially attends to the physical violation, sanctioning 'no pushing' as "no hands," which invokes an alternative method of doing things, akin to a more explicit directive such as "use your words" (cf. Kyratzis \& Köymen 2020). Again, the physicality of the boys' exchange is a problem that is generally found 
in children's interactions across various school contexts. For many D/HH children, however, there is perhaps a greater temptation to use physical grabbing and pushing to resolve problems because they are not accustomed to using their voices as much as hearing children (Theunissen, Rieffe, Kouwenberg, De Raeve, Soede, Briaire, \& Frijns 2014). The solution in this exchange is to not only sanction Brian's physical action but also to model the alternative behavior of spoken language. Ms. Kate works to reorient Brian by prompting him to orally communicate his intentions ("What do you want him to do?"), and when Brian answers ("I want him to move"), he subsequently must articulate this intention to Aaron directly. Thus, Ms. Kate helps Brian to control his impulses while simultaneously teaching him more acceptable ways to solve problems, with acceptability resting on vocalization (Kyratzis \& Köymen 2020). Brian is encouraged to believe that vocalizing your wants will get you what you need. However, unlike the previous example, Brian initially DOES use speech, although minimally; therefore, it is not that any form of vocalization is morally valued. Although 'no pushing' is taken up by the instructor first, Brian's lack of appropriate speech becomes the more sanctionable breach, as the instructor could have simply ended her intervention with "No hands!", but instead continues to hold Brian morally accountable for his limited language use. To underscore this point, note that Brian is not required to apologize for his behavior in this exchange, which downplays his push as a moral violation.

This example adds dimension to what is considered 'nice' in the oral classroom. Where the previous subsection showed how children can be sanctioned for improperly making requests or demands, so too can they be sanctioned when using physical force with each other (Tobin et al. 1989). These transgressions, however, are quite dissimilar, yet in both situations the children are sanctioned for not doing something 'nicely'. In the oral classroom, then, 'being nice' primarily entails the use of oral communication, which can consequently socialize children to the view that non-oral communication is somehow inappropriate or unkind.

In a separate incident during free-play, Ms. Kate witnesses Aaron pushing Ivan and running away.

\footnotetext{
"Aaron, no pushing!" scolds Ms. Kate. The two children freeze and stare at her. She questions Aaron on the reason behind his pushing and, when none is given, orders him to apologize to Ivan. Aaron timorously hurries over to Ivan but says nothing. He looks sad and embarrassed, his apology is faint, almost in a whisper, and then his eyes tear up. Ms. Kate walks over and kneels between the children. "Thank you for apologizing, Aaron. It's okay, don't be sad," she says comfortingly. "But we don't push our friends. That's not nice." She then turns toward Ivan. "Aaron said he's sorry. What do you want to say to your friend?" Ivan responds, "It's okay.” Ms. Kate stands up. "Good. No more pushing, alright?"
}

Different from the previous examples, Ms. Kate DOES seek an account for misbehavior in this exchange, but when no account is forthcoming, she orders an apology from Aaron, effectively attributing guilt to him. Aaron produces a strong emotional display to this ascription of guilt and proceeds to apologize to Ivan. Up until this point, Ms. Kate initiated what Björk-Willén (2018) defined as an apology ritual, a multistep process including identifying the conflict, emphasizing 
the moral order by exposing the wrongdoing, and demanding an apology, with this last step sometimes accompanied with further acts of conciliation between children. Indeed, we see this additional conciliation as Ms. Kate engages in a type of etiquette lesson with Ivan as a recipient of an apology, positioning him as already knowledgeable of the practices expected of members during such events ("What do want to say to your friend?"). Thus, what is especially compelling in this example is that only one child is held responsible for the violation, yet the nontransgressor is also held accountable for vocalization, further illuminating the moral implications of vocalization for maintaining interpersonal relationships. While research has shown how adults can encourage a child's vocalization in conflict so as to facilitate understandings of the transgressed-upon child's hurt feelings (Kyratzis \& Köymen 2020), in this example, orienting to even the transgressedupon child's vocalization underscores the principle of 'talking it out' as a shared project and, most importantly, the imperative of getting the children to use their speech. Ultimately, the conflict is not resolved until Ivan vocally absolves Aaron.

To conclude this subsection, in episodes of children's disputes, we see how the instructor promotes students' development of moral judgements through her socialization messages targeted at oral conflict-resolution strategies, which instill prosocial values such as self-regulation, cooperation, treating others respectfully, and maintaining friendships. This can be accomplished by enforcing the interactional routine of 'talking it out', by seeking accounts of responsibility from students, by familiarizing students with ritual practices such as apologies, and by modeling more acceptable or effective formulations of spoken language used in disputes, all of which are designed to condition the children to use more of their voice. In the above excerpts, hitting, grabbing, and pushing are treated as moral problems that could have potentially been avoided if the children had vocalized their feelings or tensions, enabling their understandings of each other and of the social activity in which they take part. This, then, is the fundamental breach in the moral order: Children's vocalizations are accountably withheld or missing (Schegloff 2007), with accountability in the sense that their neglect of oral speech denies the normative foundations of intersubjectivity and intelligible, joint social actions (Garfinkel 1967). This is prioritized over the moral accountability of untoward acts such as pushing or hitting. Ms. Kate promotes the children's moral behavior and character by encouraging their conformity to the norm of vocalization, which allows for positive social interactions and relations. Similar to students' requests, peer conflicts present an opportunity for informal teaching moments in the sense that the instructor treats these mundane interactions as a vehicle for socialization into vocalization.

\section{Negotiating children's participation in classroom activities}

In the oral classroom, children's participation in formal lessons and activities requires that they make explicit their status as both speakers and hearers by vocally addressing and responding to other co-present members, respectively. Failing to 
vocalize is oriented to by the instructor and teaching aides as failing to cooperate in the participation framework (Goffman 1981). This is perhaps most critical in classroom lessons, where teachers are directly calling upon students to assess their competence of whatever subject the lesson is focused on. However, in the oral classroom, even students' CORRECT answers, produced through gesture or other embodied action, are regarded as insufficient if not spoken. The excerpts below describe common instances during lessons where students use non-vocal responses to the teachers' initial questions, and the teachers subsequently negotiate what is and is not an acceptable answer. In the first example, Ms. Kate has just finished reading the children's folktale, The Gingerbread Boy, and has set up an activity where the children reenact the storyline. The class reenacts a scene where the Gingerbread Boy accepts a sly fox's offer to ride on his back across a river.

\footnotetext{
Ms. Kate asks the class, "And what did the fox do with the Gingerbread Boy?" Beaux pretends to take a big bite of something and puffs up his cheeks. Ms. Kate affirmingly nods and points to him, "What did he do?" The other students look at Beaux, who begins to re-perform his pantomime, but Ms. Kate stops him. "No, can you tell me?" He pauses, then recounts that the fox ate the Gingerbread Boy. "Yes, good listening, Beaux!" says Ms. Kate. "The fox gobbles him up!"
}

Here, although Beaux demonstrates successful narrative comprehension through his bodily re-enactment, and Ms. Kate clearly understands what he is conveying, his correct answer to her question is not accepted until he vocalizes the very same scenario he is acting. Having nodded and pointed to Beaux, which indicates approval, Ms. Kate positions him as a model for his fellow classmates, who then collectively direct their attention to him. Yet, it is only Beaux's vocalized answer that is ultimately accepted as a contribution to the ongoing lesson. His oral description of the story is then attributed to and is praised for his good listening, however, the value of listening is not evaluated by the instructor until Beaux first complies with the moral imperative of vocalization.

Displays of poor listening (or worse, outright inattention) are treated by the teachers as moral offenses stemming from violations of the basic rules of conversational turn-taking (Sacks, Schegloff, \& Jefferson 1974). This next example involves a one-on-one lesson where Ms. Brooke holds up cards that display different colored shapes, and Evie, equipped with a dry-erase board and markers, is to copy and draw what is printed on the card.

\footnotetext{
Brooke holds up a card with five blue circles. Evie takes the blue marker and begins to draw. Brooke asks what she's drawing, but Evie doesn't respond and stays focused on her dry-erase board. Brooke pursues, "Can you tell me what you're drawing?" Again, Evie stays silently fixated on her circles, which she has so far drawn correctly to match the card. Brooke sets her hands down on Evie's board, making Evie pause and look up. "I'm talking to you, Evie," Brooke says gently. "You need to answer me when I ask you something. What are you drawing?" Evie looks at her board and replies, "Circles." Brooke asks, "What kind of circles?" Brooke goes back and forth with Evie until Evie eventually says, "I'm drawing five blue circles."
}

Similar to Beaux in the previous example, Evie displays comprehension of the actual matching task at hand; however, Ms. Brooke suspends the activity to ensure 
Evie's oral-communication competency, implicating an underlying agenda which we can now clearly recognize as getting the students to use their words. Importantly, having asked Evie a question, Ms. Brooke orients to the lack of response, in a relevant response space, as noticeably absent and thus accountably missing (Schegloff 2007). This warrants her pursuit of a vocal response, in which a lesson on interactional etiquette transpires. In other words, a lesson within a lesson unfolds as Ms. Brooke inculcates the social conventions of interaction, which is itself imbued with morality towards social solidarity. From here, it is not that any response will suffice, as Ms. Brooke's preferences are revealed in the gradual progression of Evie's utterances until a maximized, sentential response is ultimately accepted. It is worth mentioning that it is not uncommon for children to ignore adults when they are immersed in something; however, in this exchange, a question arises if Evie's initial unresponsiveness is attributed to her D/HH status. To note, Ms. Brooke does not inquire, "Did you hear me?". Instead, she insists on speech in response rather than simple acknowledgement of being heard. Furthermore, this example shows how moral features are encoded in different forms of language, which can collectively discourage the children's use of one form of language (e.g. minimal responses) in favor of adopting another (e.g. using full sentences) and, in doing so, encourages the children's accommodation to the language ideology in the oral classroom (Ochs \& Schieffelin 1995). To be sure, eliciting full sentences from children represents a general pedagogical objective of improving linguistic comprehension, and thus the exchange between Ms. Brooke and Evie might not be unique to the oral classroom. However, what should be clear by now is that the morality of vocalization is always intertwined with whatever task, lesson, activity, or course of action participants are engaged in on a moment-to-moment basis.

\section{I S C U S S I O N}

The aim of this study was to elucidate how children's vocalizations are oriented to as having moral significance in themselves, which organizes social behavior in the oral classroom in particular ways. Specifically, analyses reveal that, though certain goals (interactional goals like turn-taking, instructional goals like sentencebuilding, or interpersonal goals such as demonstrating prosocial behaviors) may indeed be oriented to by participants, it is the imperative of students' use of speech that permeates and is consistently prioritized in classroom activities. Socialization into vocalization occurs both in formal lessons and informal activities (e.g. when children ask for help or in peer disputes), highlighting both explicit and implicit messages regarding the 'rules' and value of using spoken language. While many of the teachers' practices that were demonstrated in the analyses have been discussed in previous research, the main contribution of the present study is its focus on participants' overt orientations to vocalization as a constitutive practice in their oral classroom, such that it is normatively expected in the production of social actions in classroom interaction. 
The advantages of this study include its qualitative focus on children's interactions to examine the mechanisms involved in the ongoing accomplishments of moral reasoning, which can complement the more traditional survey or experimental methods that are common in sociological and psychological studies of morality. That is, the interaction order reveals what participants orient to as normative and, in doing so, underscores how language is essential to moral socialization and moral action, thus providing a foundation for measuring children's moral development and judgments (Tappan 2006). This has implications for theoretical developments in moral socialization, and also contributes to recent work on moral ideologies that are intertwined with communication modalities (Riley 2011). The data also emphasize the interconnection between microanalytical concerns and larger macro-level issues. Specifically, this study shows how the children in the oral classroom are socialized to messages that present spoken language as the preferred, superior form of communication, which consequently presents non-vocal communication as somehow less than or undesirable. This has implications for the competing cultural versus pathological ideologies of $\mathrm{D} / \mathrm{HH}$ children's communication and education and understanding how everyday language practices can operate as mechanisms in reproducing forms of linguistic and social inequality (Schieffelin et al. 1998).

As a study of a single oral classroom, this project has limitations for generalizability. However, since this classroom follows a broader oral-educational approach, there is little reason to believe its social organization is entirely dissimilar from those found in other oral classrooms for $\mathrm{D} / \mathrm{HH}$ children, and thus my findings can be used to better understand and inform this larger pedagogical and ideological context. I have argued that the moral project of the oral classroom is not just about fostering D/HH children's academic and social development, but also about building their dispositions for using oral language in preparation for futures in a predominantly hearing world. Accordingly, future research would do well to conduct a longitudinal study of D/HH children's oral-communication habits once they transition into mainstream settings. By exploring the social interactions of $\mathrm{D} / \mathrm{HH}$ children who are in the beginning years of oral, formal education, we can begin to uncover the complexities involved in 'using your words' and, specifically, in establishing spoken language and listening as preconditions for standard, moral behavior in the oral classroom.

\section{N O T E S}

*I'd like to thank Stefan Timmermans and Tanya Stivers for their guidance in developing this project from a thesis paper into a journal article. I'd also like to thank the anonymous reviewers for their insightful comments.

${ }^{1}$ In brief, the uppercase D in Deaf typically refers to someone who identifies as culturally Deaf, while the lowercase $\mathrm{d}$ refers to the audiological condition or to someone who does not identify with Deaf culture. In this article, I use lowercase d to refer to the children's audiological diagnoses that made them eligible for placement in the oral classroom.

${ }^{2}$ I chose to use the term vocalization rather than verbalization to reflect the classroom's preference of communicating with your voice and not always necessarily with lexically meaningfully utterances. 


\section{'USE YOUR WORDS'}

For example, sometimes students will produce vocal utterances that are not always comprehensible as words, though the teachers may treat them as more acceptable conversational turns relative to gestures or other non-verbal ones.

${ }^{3}$ Throughout the article, terms such as hearing loss or hearing impairment reflect the language used in the US Individual with Disabilities Act.

${ }^{4}$ While the sociopolitical background of these competing ideologies is important, due to space constraints and my particular foci, I am unable to offer a more thorough discussion of this controversy.

${ }^{5}$ I do not claim the oral approach as better for D/HH children's education. Rather, I focused exclusively on oral education because I was already a volunteer in an oral classroom, which facilitated data collection for this project.

\section{R E F E R E N C ES}

Ahn, Junehui (2016). 'Don't cry, you're not a baby!': Emotion, role and hierarchy in Korean language socialisation practice. Children \& Society 30(1):12-24.

Björk-Willén, Polly (2018). Learning to apologize: Moral socialization as an interactional practice in preschool. Research on Children and Social Interaction 2(2):177-94.

Bowen, Sandra K., \& Kay Alicyn Ferrell (2003). Assessment in low-incidence disabilities: The day-to-day realities. Rural Special Education Quarterly 22(4):10-19.

Burdelski, Matthew (2010). Socializing politeness routines: Action, other-orientation, and embodiment in a Japanese preschool. Journal of Pragmatics 42(6):1606-21.

(2015). Reported speech as cultural gloss and directive: Socializing norms of speaking and acting in Japanese caregiver-child triadic interaction. Text \& Talk 35(5):575-95.

(2020). 'Say can I borrow it': Teachers and children managing peer conflict in a Japanese preschool. Linguistics and Education 59, article 100728. Online: https://www.researchgate.net/ publication/345396096_'Say_can_I_borrow_it'_Teachers_and_children_managing_peer_conflict_ in_a_Japanese_preschool_Free_download_for_50_days_httpsauthorselseviercoma1c1Zi3CKC7EwpLI.

Cekaite, Asta (2012). Tattling and dispute resolution: Moral order, emotions, and embodiment in teachermediated disputes of young second language learners. In Susan Danby \& Maryanne Theobald (eds.), Disputes in everyday life: Social and moral orders of children and young people, 165-93. Bingley: Emerald Group.

(2013). Socializing emotionally and morally appropriate peer group conduct through classroom discourse. Linguistics and Education 24(4):511-22.

(2020). Triadic conflict mediation as socialization into perspective taking in Swedish preschools. Linguistics and Education 59, article 100753. Online: https://www.researchgate.net/publication/ 336992503_Triadic_conflict_mediation_as_socialization_into_perspective_taking_in_Swedish_ preschools.

— \& Ann-Carita Evaldsson (2020). The moral character of emotion work in adult-child interactions. Text \& Talk 40(5):563-72.

Charmaz, Kathy (2006). Constructing grounded theory: A practical guide through qualitative analysis. London: SAGE.

Corsaro, William A. (2017). The sociology of childhood. Thousand Oaks, CA: SAGE.

Danby, Susan, \& Carolyn Baker (1998). 'What's the problem?': Restoring social order in the preschool classroom. In Ian Hutchby \& Jo Moran-Ellis (eds.), Children and social competence: Arenas of action, 159-85. London: Falmer Press.

DeVries, Rheta, \& Betty Zan (1994). Moral classrooms, moral children: Creating a constructivist atmosphere in early education. New York: Teachers College Press.

Garfinkel, Harold (1967). Studies in ethnomethodology. Cambridge: Polity.

— \& Harvey Sacks (1970). On formal structures of practical action. In John C. McKinney \& Edward A. Tiryakian (eds.), Theoretical sociology: Perspectives and developments, 338-66. New York: Appleton Century-Crofts. 


\section{KRISTELLA MONTIEGEL}

Goffman, Erving (1981). Forms of talk. Philadelphia: University of Pennsylvania Press.

(1983). The interaction order: American Sociological Association, 1982 presidential address. American Sociological Review 48(1):1-17.

Goodwin, Marjorie H., \& Amy Kyratzis (2007). Children socializing children: Practices for negotiating the social order among peers. Research on Language and Social Interaction 40(4):279-89.

Heritage, John (1984). Garfinkel and ethnomethodology. Cambridge: Polity.

(2001). Goffman, Garfinkel, and conversation analysis. In Margaret Wetherell, Stephanie J. Taylor, \& Simeon J. Yates (eds.), Discourse theory and practice: A reader, 47-57. London: SAGE.

Hitlin, Steven, \& Stephen Vaisey (eds.) (2010). Handbook of the sociology of morality. New York: Springer.

Holm Kvist, Malva (2018). Children's crying in play conflicts: A locus for moral and emotional socialization. Research on Children and Social Interaction 2(2):153-76.

Howard, Kathryn M. (2017). Language socialization language ideologies, and language shift among school-aged children. In Patricia A. Duff \& Stephen Springer (eds.), Language socialization. Cham: Springer.

Jayyusi, Lena (1991). Values and moral judgement: Communicative praxis as moral order. In Graham Button (ed.), Ethnomethodology and the human sciences, 227-51. Cambridge: Cambridge University Press.

Kemp, Jacqueline, \& Amy Kyratzis (2018). Moral order among members of a friendship group of preschool boys. Research on Children and Social Interaction 2(2):235-61.

Kroskrity, Paul V. (2004). Language ideologies. In Alessandro Duranti (ed.), A companion to linguistic anthropology, 496-517. Malden, MA: Blackwell.

Kulick, Don, \& Bambi B. Schieffelin (2004). Language socialization. In Alessandro Duranti (ed.), A companion to linguistic anthropology, 349-68. Malden, MA: Blackwell.

Kyratzis, Amy, \& Bahar Köymen (2020). Morality-in-interaction: Toddlers' recyclings of institutional discourses of feeling during peer disputes in daycare. Text \& Talk 40(5):623-42.

Mayall, Berry (2002). Towards a sociology for childhood: Thinking from children's lives. Buckingham: Open University Press.

Maynard, Douglas W., \& Jason Turowetz (2013). Language use and social interaction. In John DeLamater \& Amanda Ward (eds.), Handbook of social psychology, 2nd edn., 251-79. New York: Springer.

Mitchell, Ross E., \& Michael M. Karchmer (2004). Chasing the mythical ten percent: Parental hearing status of deaf and hard of hearing students in the United States. Sign Language Studies 4(2):138-63.

Montiegel, Kristella (2021). Other-initiated repair and preference principles in an oral classroom. Journal of Pragmatics 178:108-20.

Moore, Ekaterina, \& Matthew Burdelski (2019). Peer conflict and language socialization in preschool: Introduction to special issue. Linguistics and Education 59, article 100758. Online: https://www. researchgate.net/publication/336338894_Peer_conflict_and_language_socialization_in_preschool_ Introduction_to_special_issue.

Niemi, Kreeta (2016). Moral beings and becomings: Children's moral practices in classroom peer interaction. Jyväskylä: University of Jyväskylä PhD dissertation.

Ochs, Elinor, \& Bambi Schieffelin (1995). The impact of language socialization on grammatical development. In Paul Fletcher \& Brian MacWhinney (eds.), Handbook of child language, 73-94. Oxford: Blackwell.

Pray, Janet L., \& I. King Jordan (2010). The Deaf community and culture at a crossroads: Issues and challenges. Journal of Social Work in Disability \& Rehabilitation 9(2-3):168-93.

Rawls, Anne Warfield (1987). The interaction order sui generis: Goffman's contribution to social theory. Sociological Theory 5(2):136-49.

- (2010). Social order as moral order. In Steven Hitlin \& Stephen Vaisey (eds.), Handbook of the sociology of morality, 95-121. New York: Springer.

(2012). Durkheim's theory of modernity: Self-regulating practices as constitutive orders of social and moral facts. Journal of Classical Sociology 12(3-4):479-512. 


\section{'USE YOUR WORDS'}

Riley, Kathleen C. (2011). Language socialization and language ideologies. In Alessandro Duranti, Elinor Ochs, \& Bambi B. Schieffelin (eds.), Handbook of language socialization, 493-514. West Sussex: Wiley.

Sacks, Harvey; Emanuel A. Schegloff; \& Gail Jefferson (1974). A simplest systematics for the organization of turn-taking for conversation. Language 50(4):696-735.

Samra-Fredericks, Dalvir (2010). Ethnomethodology and the moral accountability of interaction. Journal of Pragmatics 42(8):2147-57.

Schegloff, Emanuel A. (2007). Sequence organization in interaction: A primer in conversation analysis, vol. 1. Cambridge: Cambridge University Press.

Schieffelin, Bambi B., \& Elinor Ochs (1986). Language socialization. Annual Review of Anthropology 15(1):163-91.

— \& — Kathryn A. Woolard; \& Paul V. Kroskrity (eds.) (1998). Language ideologies: Practice and theory. Oxford: Oxford University Press.

Tappan, Mark B. (2006). Mediated moralities: Sociocultural approaches to moral development. In Melanie Killen \& Judith G. Smetana (eds.), Handbook of moral development, 351-74. New York: Taylor \& Francis.

Theunissen, Stephanie C. P. M.; Carolein Rieffe; Maartje Kouwenberg; Leo J. I. De Raeve; Wim Soede; Jeroen Briaire; \& Johan H. M. Frijns (2014). Behavioral problems in school-aged hearing-impaired children: The influence of sociodemographic, linguistic, and medical factors. European Child \& Adolescent Psychiatry 23(4):187-96.

Tobin, Joseph Jay; David Y. H. Wu; \& Dana H. Davidson (1989). Preschool in three cultures: Japan, China, and the United States. New Haven, CT: Yale University Press.

Turowetz, Jason J., \& Douglas W. Maynard (2010). Morality in the social interactional and discursive world of everyday life. In Steven Hitlin \& Stephen Vaisey (eds.), Handbook of the sociology of morality, 503-26. New York: Springer.

Wainryb, Cecelia, \& Holly E. Recchia (eds.) (2014). Talking about right and wrong: Parent-child conversations as contexts for moral development. Cambridge: Cambridge University Press.

Watson, Rod (2009). Constitutive practices and Garfinkel's notion of trust: Revisited. Journal of Classical Sociology 9(4):475-99.

(Received 6 December 2020; revision received 29 April 2021; accepted 11 May 2021; final revision received 13 May 2021)

Address for correspondence:

Kristella Montiegel

University of California, Los Angeles

Department of Sociology

375 Portola Plaza, Los Angeles, CA 90095, USA

kmontiegel@g.ucla.edu 